\title{
Floods of tears but nobody drowned: a resident dies unexpectedly
}

\author{
JoSEPHINe ANNe RichaRds, Registrar in Psychiatry, Towers Hospital, Gipsy Lane, \\ Leicester LE5 0TD
}

When I began my six month placement at The Lodge, an in-patient therapeutic community for those with emotional and personality disorders, there were 13 residents. Three left and two more joined us over the following month. Our consultant was on annual leave when the community was devastated by the unexpected death of a long-standing resident, who I will refer to as $B$. At the time of his death he was a well integrated member of the community.

The difficulties encountered over the ensuing five months should be viewed against our consultant's prolonged absences due to ill health. We were fortunate that a locum, with considerable experience of The Lodge, filled the post and she was also my supervisor. Nevertheless, this was inevitably a period of uncertainty and arrangements for medical responsibility were often revised.

\section{Myaccount}

\section{Joining the community}

I chose the placement at The Lodge primarily because I wanted to gain experience in large group work. I had not considered what the community might expect of me, or how I might contribute; thus I found my first few weeks confusing as I attempted to understand my role. For the first time in my psychiatric career I was not required to see patients individually and yet there was an expectation that I would assist in the assessment and treatment of the residents despite possessing limited skills in group work. While struggling with this dilemma, it became apparent that other members of the community had definite views on my usefulness. I was to act as general practitioner. However I was far more accessible than a GP usually is, and the residents addressed me by my first name so that even this role was rather unusual.

I wondered about my responsibilities for the physical and psychiatric wellbeing of the residents. It seemed that wherever possible the whole group took responsibility for individuals' problems, and yet there were certain situations where staff and especially medical staff must assume absolute responsibility (Crocket, 1960; Main, 1946; Tollington, 1969). These and other issues pertaining to my role were discussed openly with staff during my first weeks.

I started to speak in groups early on in the placement, asking questions or offering practical and medical advice. These encounters served as polite introductions between relative strangers, and I marvelled at the emotionally charged exchanges between others.

\section{The crisis}

It was during my fifth week at The Lodge that B was admitted to a general hospital in a critical condition and died two days later. Throughout those two days staff and residents visited $B$ in hospital so that The Lodge seemed empty and the community fragmented. Although B's poor prognosis was clearly communicated to all, I suspected that this was denied by many. Death was barely mentioned until it came. A telephone call interrupted a group on a totally unrelated topic. The staff member who received the call waited until the end of the group before announcing B's death and she suggested that we all "stay together". It seemed that most people erupted into floods of tears and I felt obliged to remain at The Lodge in order to offer support. I made cups of tea which nobody drank and offered words of sympathy before making my exit. I was reminded of "breaking bad news" to relatives during medical jobs and my associated feelings of helplessness and anxiety engendered by their displays of intense distress. I was worried that somehow everyone would be irrationally angry with me as had occurred in those previous settings.

I was irritated and mystified by the staff's anguish, and wondered how they would support the residents. I identified, at this early stage, my own vague feelings of guilt relating to the death which I will discuss later.

Over the next few days the expressions of sorrow continued among both staff and residents. Community meetings were short and staff complained that they could not concentrate on groups; they seemed to prefer retreating into their office and supporting each other. I felt increasingly annoyed by the staff's fears, while wondering why they were so upset over a patient. I believed that others were idealising the deceased. Being unable to share the 
acute pangs of grief, my guilt was exacerbated. I anticipated the angry verbal outbursts of residents, but much to my relief, these were directed at those more ostensibly outside the community than to me.

I identified with the two new residents who had also been poorly acquainted with $\mathrm{B}$, and sought to represent their interests.

There were heated arguments between certain staff over treatment and management issues which, at less turbulent periods as I would witness in future, could have been dealt with through calm discussion. These disagreements were soon resolved, but nevertheless caused additional stress and presumably reflected considerable underlying tensions.

\section{Taking stock: some uncomfortable questions are raised}

I attended the staff support group and expressed my feelings of separateness from the community's grief. I was reassured that my contributions were valued and emotional distance from B's death perceived as providing a useful objective viewpoint. The staff were asking themselves about their own displays of vulnerability, and wondering how this was affecting residents.

Our consultant returned from his holiday and spoke wise words which, I believe, helped me and others. He suggested that as doctors we find it difficult to accept that the death of a patient is not due to our own incompetence or inadequate treatment. Tolerating the uncertainty of one's abilities is never easy, and the present situation served as a powerful reminder of this.

As I began to understand my feelings of failure and guilt I also recognised a desire to avoid reminders of $B$, and would have preferred to turn my attention to other, living, patients as this was how I had dealt with death at work before. Some degree of emotional detachment is, of course, protective when working in branches of medicine where one would otherwise be overwhelmed by the daily face of sorrow. This time, however, there was no escaping either the fact or the grief of others, and I wondered how I would tolerate this patient's death when my coping strategies had been so effectively removed.

I was preoccupied with surviving the placement emotionally intact, protecting my professional reputation from blame and avoiding the bereaveds' anger.

\section{The grieving process and my integration into the} therapeutic community

Much to my relief the staff soon regained control of their emotions. Groups and community meetings returned to a more respectable length. The task of supporting the residents in working through their grief began in earnest. For many, B's death reminded them of previous losses which were re-experienced and re-examined. I have already mentioned residents' anger and idealisation, but equally prominent were guilt, anxiety and later, depression. Sleeplessness and anorexia were common complaints. Others showed few overt signs of distress.

My abiding memory of The Lodge during the two or three months following B's death was of a pervasive sadness which, despite my apprehensions, did not overwhelm me but did arouse empathy. Rituals which were shared by staff and residents such as organising a memorial service, grieving in his room and sorting through his belongings presumably assisted in the resolution practice.

The depression seemed somewhat dispelled when new residents were admitted in significant numbers. This did not herald a more relaxed period for the community, however, as a multitude of other individual and group matters ensued. I gradually developed a deep respect for the staff's patience, tact and skill in dealing with the myriad of troublesome emotions regularly displayed by residents.

I had accurately predicted that I would in turn receive my share of residents' anger. The superficial issues would be medical matters. Everyone expected full explanations for my decisions which were often angrily criticised by residents. Indeed, for many, their encounters with me aroused deep seated antagonism to authority figures and perceived mistreatment and neglect from doctors in the past. It seemed that my status held little sway, and I must rely on my knowledge, communication abilities and less tangible personal qualities to gain acceptance and respect. This was threatening, but again, I coped and indeed, later in the placement had gained enough confidence to speak out openly and assertively on non-medical matters.

Another of my concerns had been that some residents might attempt suicide during the period of hopelessness and depression. Thankfully there were no significant episodes of self-harm which presumably reflected high levels of support and cohesion within the community.

On leaving The Lodge, firstly I identified with the staff's grief as I experienced loss in saying goodbye myself, and secondly, I understood that by expressing and dealing with their own emotions, this had enabled staff to subsequently support the residents (Whiteley \& Gordon, 1979). I found that no one blamed me for B's death, and my own guilt subsided.

\section{Concluding remarks}

In this account I have identified grieving processes both in individuals and the group. It seemed that, for residents, resolution of grief was accompanied by a degree of emotional maturation and that the crucial ingredients in achieving this were the opportunities, 
unique to a therapeutic community, for sharing emotions and support.

I have explored some of my own difficulties confronting death both at personal and professional levels, and attempted to place these in the social contexts of the therapeutic community and society at large.

I have learnt that if I relinquish some of my status I am not destroyed by the anger of patients and if $I$ allow myself to empathise with their pain I am not engulfed. Similarly I believe that my ability to communicate with patients and confidence to withstand their criticism were enhanced by working at The Lodge.

I began this account by raising questions about my role at The Lodge and wondering how I might contribute to the assessment and treatment of the residents. It seems, on reflection, that what was required most were very basic human qualities such as caring, common sense, courage, self-confidence, and a degree of introspection. I would recommend that all training psychiatrists spend a period at a therapeutic community if they have the opportunity. Some of us may need to rediscover those skills, and may even be surprised that others will value our contributions.

\section{References}

Crocket, R. W. (1960) Doctor, administrator and the therapeutic community. Lancet, ii, 359-363.

MAIN, T. F. (1946) The hospital as a therapeutic institution. Bulletin of the Menninger Clinic, 10, 66-70.

Tollington, H. J. (1969) The organisation of a psychotherapeutic community. British Journal of Medical Psychology, 42, 271-275.

Whiteley, J. S. \& GoRDON, J. (1979) Group Approaches in Psychiatry. London, Boston \& Henley: Routledge \& Kegan Paul.

\section{Saudi Arabian Diploma and Fellowship in Psychiatry}

The Diploma and Fellowship Examinations in Psychiatry were held at the King Saud University, College of Medicine, and King Khalid Hospital, Riyadh, Saudi Arabia in October/November 1992.

The training programme is based on the Royal College model and is organised by Dr Abdulrazzak Alhamad (Co-ordinator for Diploma and Fellowship Programmes in Psychiatry), Dr A. Al-Subaie, FRCP (C), and Dr Fateh El Aleem M. Abdul Rahim, MRCPsych.
The Fellowship Examination was taken by four candidates, of whom three passed: Dr Daad M. Mardini, Dr K. AlSabhan, and Dr M. AlSawaf.

The successful candidates will now take on senior registrar status.

The examiners were Dr Abdul Elkarim Ahmed Osman, MRCPsych, Professor M. Fakhr ElIslam, FRCPsych and Professor Greg Wilkinson, FRCPsych. 